REVISTA DE DERECHO UNED, núm. 2, 2007

\title{
LAS BASES JURÍDICO-CONSTITUCIONALES DEL PROCESO DE DESCENTRALIZACIÓN EN FRANCIA ${ }^{1}$
}

\author{
AlBerto ANGUita SusI \\ Profesor de Derecho Constitucional \\ Universidad de Jaén
}

Resumen: Cualquier proceso de descentralización requiere que los gobiernos territoriales sean designados mediante un sistema electoral democrático y que las colectividades territoriales dispongan de un ámbito propio y autónomo de actuación normativa. Para lograr este objetivo se han adoptado en Francia una serie de medidas normativas y políticas cuyos resultados no responden, en sentido estricto, a la lógica de una auténtica descentralización; pudiéndose hablar de la consecución de un cierto grado de semi-descentralización o, si se prefiere, de una descentralización imperfecta o relativa.

Ello es debido a que la reforma constitucional operada en Francia posee una impronta programática e idealista que convierte al legislador orgánico en el protagonista para dotar al proceso de descentralización de "realismo jurídico»; otra cosa es que el reconocimiento constitucional de una serie de «nuevos principios» sirva para que la descentralización en Francia se convierta en un elemento constitutivo de su identidad política y no una mera forma de organización administrativa del Estado.

Palabras clave: Francia, Descentralización, Departamentos.

1 Este trabajo ha sido realizado utilizando la bibliografía y documentación recopilada por el autor con motivo de una estancia de investigación en el Centro de Estudios Jurídicos y Doctorales de la Universidad Paris I (Panthéon-Sorbonne), bajo la coordinación del Prof. Dr. Gerard Marcou, durante los meses de mayo y junio de 2006. 
Abstract: Every decentralization process requires for the territorial governments to be designed by the means of a democratic electoral system and for the territorial collectivities to dispose of a self-government including autonomous legislative powers. In order to achieve this objective France has enacted a series of political and legal measures, but the result isn't strictly what is recognized as the logic of an authentic decentralization; moreover, it would be more appropriate to register the achievement of a certain degree of semi-decentralization or preferably of an imperfect or relative decentralization. What said is owed to the French constitutional reformation, it, leaving a programmatic and idealistic print, by converting the organic legislator into the main institutional character, the only who can enrich the decentralization process with "legislative realism". Differently the constitutional absorbing of a series of "new principals" helps rendering the French decentralization an element that constitutes its political identity and not a simple administrative detachment of the state organization.

Key words: France. Decentralizatión. Territorial Governments.

Sumario: I. INTRODUCCIÓN: SIGNIFICADO Y ALCANCE DE LA DESCENTRALIZACIÓN.-II. ANTECEDENTES HISTÓRICOS Y CONTEXTO JURÍDICO DE LA DESCENTRALIZACIÓN EN FRANCIA.-III. LAS BASES CONSTITUCIONALES DE LA DESCENTRALIZACION: REFERENCIA A LA REFORMA CONSTITUCIONAL DE 2003.-IV. CONCLUSIONES: ALCANCE Y PERSPECTIVAS DEL PROCESO DESCENTRALIZADOR EN FRANCIA

\section{INTRODUCCIÓN: SIGNIFICADO Y ALCANCE DE LA DESCENTRALIZACIÓN}

La precisa delimitación del complejo y poliédrico fenómeno de la descentralización resulta especialmente necesaria en el caso de Francia, habida cuenta de que la tradición histórica y jurídica de este país ha venido mostrando una férrea y jacobina tendencia hacia el centralismo y la unidad².

${ }^{2}$ Como apunta acertadamente sobre este particular el prof. G. DuPUIS, rebatiendo en este punto al propio Alexis de Tocqueville, la centralización en Francia no es una conquista propia de la Revolución liberal, sino más bien un producto del Antiguo Régimen acentuado por la Revolución y por el régimen de Napoleón Bonaparte. (Le cen 
Entre las diversas perspectivas desde las cuales cabe analizar cualquier proceso de descentralización, en este trabajo nos centraremos en la jurídica y la política ${ }^{3}$. Desde un punto de vista político, la descentralización se sustenta tanto en el grado de libertad política de las entidades territoriales como en el control que ejerce el pueblo soberano $^{4}$. Por su parte, la vertiente jurídica de la descentralización implica el reconocimiento de personalidad jurídica y de un entramado organizativo que sirva a las colectividades territoriales para administrar autónomamente sus propios intereses.

En síntesis, para que la descentralización pueda ser calificada de auténticamente democrática resulta indispensable, por un lado, que las autoridades administrativas territoriales no sean designadas por el poder central, sino mediante un sistema electoral democrático ${ }^{5} \mathrm{y}$, por otro, que las colectividades territoriales dispongan de un ámbito propio y autónomo de actuación normativa. La descentralización no es más que el reconocimiento, por parte del Estado, de la diversidad y de la autonomía de sus componentes territoriales con el fin de sa-

tre et la périphérie en France, L.G.D.J., Paris, 2000, págs. 15 y 17). En el mismo sentido se pronuncia DuboIS J.P., "Décentralisation, idée révolutionnaire?", en AAVV (Dir. MOREAU J. et VERPEAUX M.)., Revolution et décentralisation. Le systeme administratif français et les principes revolutionnaires de 1789, Actes du Colloque de Besançon, 1415 décembre 1989, Collection Droit Public Positif, Ed. Economica, Paris, 1992. En los debates de este Coloquio, R. DEBBASCH matiza con acierto que tras la Constituyente revolucionaria, Francia pasó de la "diversidad centralizada" del Antiguo Régimen a la «uniformidad descentralizada». Sobre este tema se puede consultar el documentado trabajo de GuINARD D., La notion d'uniformité en Droit public français, Dalloz, Paris, 2004.

3 Sobre el concepto de descentralización véase a Flogaïtis S., La notion de décentralisation en France, en Allemagne et en Italie, L.G.D.J., Paris, 1979. Más precisamente, y por lo que se refiere a la interrelación entre la descentralización política y jurídica, hay que señalar, como sostiene J. BAGUENARD, que todo proceso de descentralización política exige previamente una auténtica descentralización jurídica. (La décentralisation territoriale, Presses Universitaires de France, Paris, 1980, pág. 74).

${ }^{4}$ Como señala Y. MENY, citando a Hauriou, la descentralización no es más que un proceso tendente a crear centros de poder autónomos y legitimados por elección popular; de manera que no persigue tanto asegurar una mejor y más eficaz gestión de los asuntos públicos, sino promover una participación más democrática de los ciudadanos. (Centralisation et décentralisation dans le débat politique français (19451969), L.G.D.J., Paris, 1974, pág. 31).

5 Pese a esto, resulta indudable que el carácter democrático de la descentralización subsiste cuando las autoridades territoriales son nombradas por el poder central pero no representan a éste, dado que sus actos están sometidos a un simple poder de control no jerárquico. Esta idea ha sido defendida, entre otros, por BOURJOL M., «Libre administration et décentralisation», en AAVV., Vertus et limites de la décentralisation, Colloque des 2 et 3 mai 1985. Université de Clermont-Ferrand, Les Cahiers du Droit Public, 1985, pág. 68. 
tisfacer la legítima aspiración del pueblo a participar en la gestión de sus intereses ${ }^{6}$.

Para lograr este objetivo se han adoptado en Francia una serie de medidas normativas y políticas cuyos resultados no responden, en sentido estricto, a la lógica de una auténtica descentralización; pudiéndose hablar, a lo sumo, de la consecución de un cierto grado de semi-descentralización o, si se prefiere, de descentralización imperfecta o relativa ${ }^{7}$, debido, sobre todo, a la persistencia de una relación jerárquica entre el nivel central y el territorial. Dicho en otras palabras, en Francia la descentralización no es el elemento constitutivo de su identidad política, sino más bien la forma de organización administrativa del Estado.

La cuestión que se suscita, pues, reside en analizar si la dimensión constitucional que el proceso de descentralización ha adquirido en Francia tras la reforma de $2003^{8}$ servirá para alcanzar el equilibrio entre la unidad y la diversidad, logrando una «unidad pluralista» antes que un «pluralismo unitario»?

${ }^{6}$ En este sentido, cabría afirmar que «la descentralización a la francesa es sinónimo de democracia territorial o de democracia de proximidad». (MELLA E. et KISSANGOULA J., "Le vrai visage de la décentralisation», en Révue Générale des Collectivités Territoriales, n. ${ }^{\circ}$ 23, 2002, pág. 180). De la misma opinión es J.C. NÉMERY, para quien en una República territorialmente descentralizada o de proximidad, el Estado debe promover el desarrollo de los territorios, procurar que las decisiones sean adoptadas de la forma más cercana a los ciudadanos y según un modelo compatible con los principios de equidad territorial y de justo equilibrio en el reparto de recursos públicos entre los territorios. ( «Reforme de la décentralisation et transferts de compétences», en AAVV., Réforme de la décentralisation, réfome de l'État, Régions et Villes en Europe, Annuaire des collectivités locales 2004, CNRS Editions, Paris). En este sentido puede verse a CAILLOSSE J., «La décentralisation, une ruse de l'État central?», en Révue Pouvoirs Locaux, n. ${ }^{\circ}$ 63, 2004, págs. 43 a 53.

7 Sobre este aspecto consúltese, para mayor abundamiento, a AUBRY F.X., La Décentralisation conre l'État (L'État semi-centralisé), L.G.D.J., Paris, 1992, pág. 168. Este autor resume de manera clara y precisa los distintos posicionamientos doctrinales, así como los elementos que permitirían distinguir entre un sistema centralizado, semicentralizado, semi-descentralizado y descentralizado.

8 PONTIER J. M., «La République décentralisée de J.P. Raffarin», en La Revue Administrative, n. ${ }^{\circ} 332,2003$, pág. 188.

9 Parte de la doctrina francesa no está muy de acuerdo con estos postulados. En este sentido, F.X. AUBRY considera que la descentralización no es tanto un fenómeno político sino, más bien, una ficción jurídica. Es más, la descentralización es reveladora de la crisis del orden jurídico, que incluso puede ser vista como un pretexto para proteger paralelamente los postulados del Estado unitario, pero en ningún caso como la consecución de un pluralismo jurídico. (La Décentralisation contre l'État (L'État semi-centralisé), op. cit. pág. 79). Por el contrario, P. DOLLAT entiende que es necesario abandonar progresivamente la uniformidad en beneficio de la unidad, a fin de consolidar el pluralismo y la diversidad democrática. («Le principe d'indivisibilité 


\section{ANTECEDENTES HISTÓRICOS Y CONTEXTO JURÍDICO DE LA DESCENTRALIZACIÓN EN FRANCIA}

La historia de la organización territorial en Francia ha pasado por una serie de etapas cuyo punto de partida fue la Revolución liberal de 1789. Como es sabido, uno de los grandes ideales y fines de la Revolución fue acabar con los particularismos y la fragmentación territorial, así como con los privilegios propios del Antiguo Régimen, lo que propició una defensa a ultranza de la unidad y la uniformidad del sistema político. Pese a ello, en 1789 se crearon los departamentos ${ }^{10}$, que conforman la unidad territorial básica que ha pervivido en Francia hasta nuestros días, lo cual no es sino una demostración de que los revolucionarios procuraron también descentralizar el poder a través de la instauración de entidades capacitadas para ejercer funciones propias $^{11}$. De todas formas, no hay que olvidar que los departamentos funcionan como una instancia de transmisión y ejecución de las órdenes que provienen del Estado central ${ }^{12}$.

El verdadero punto de inflexión vino marcado por la Convención de 25 de septiembre de 1792, la cual proclamaba sin ambages que la «República francesa es una e indivisible» ${ }^{13}$. Como consecuencia de este principio fundamental, el sistema napoleónico instauró la figura del prefecto, cuya misión no era otra que dar unidad a la actuación gubernamental y a las políticas a desarrollar en cada departamento. Hasta 1830, la estructura territorial francesa se componía de departamentos, municipios y distritos. A partir de esta fecha la adminis-

et la loi constitutionnelle relative à l'organisation décentralisée de la République française: de l'État unitaire à l'État uni?», en Révue Française de Droit Administratif, n. ${ }^{\circ} 4,2003$, págs. 670 y 671 ).

${ }^{10}$ En virtud de la Ley de 22 de diciembre de 1789, Francia quedó divida en departamentos, aunque curiosamente esta Ley sólo utilizaba este concepto en su artículo primero. Además, la división departamental no fue solamente administrativa sino que sirvió de base para la designación de diputados de los futuros cuerpos legislativos. En otras palabras, los departamentos fueron una nueva colectividad pero, sobre todo, constituyeron la base de la división territorial y la representación nacional. Para un mayor desarrollo de esta idea véase a BODINEAU P. et VERPEAUX M., Histoire de la décentralisation, Presses Universitaires de France, Paris, 1993.

11 Tomamos esta idea de LUCHAIRE F. et LUCHAIRE Y., Le Droit de la décentralisation, Presses Universitaires de France, Paris, 1989, pág. 53.

12 Sobre este aspecto, puede consultarse a BERNARD P., L'État et la décentralisation. Du préfet au commissaire de la République, La Documentation Française, Paris, 1983.

${ }^{13}$ Aunque esta disposición será estudiada con mayor detenimiento cuando veamos las bases constitucionales de la descentralización, nos remitimos a HOUTEER C., Recherches sur les bases constitutionnelles de la décentralisation territoriale (Tomo II), Tesis Inédita, Université Toulouse I, 1987, págs. 549 a 601. 
tración municipal y departamental se democratizó con motivo de la entrada en vigor de la Carta de 1830; de hecho, tanto la Ley municipal de 18 de julio de 1837, como la Ley departamental de 10 de mayo de 1838, reconocían a los municipios y departamentos, respectivamente, un cierto grado de personalidad jurídica.

Los pasos dados por este conjunto de medidas normativas se consolidarían, años más tarde, con la Constitución de 1852 y con la promulgación de un Decreto de 25 de marzo de 1852, cuyo contenido auspiciaba la tendencia hacia un proceso de descentralización, al menos desde un punto de vista administrativo, que quedaba condensado en la fórmula: se puede gobernar de lejos, pero sólo se puede administrar bien de cerca. Esta tendencia tuvo su continuidad con el llamado "Programa de Nancy», cuya célebre proclama, además de dejar una profunda huella en el devenir del proceso de descentralización, sigue teniendo aún hoy plena vigencia: "Lo que es nacional para el Estado, lo que es regional para la Región, lo que es municipal para el Municipio ${ }^{14}$.

Con algunos altibajos, puede decirse que durante la segunda mitad del siglo XIX y el primer tercio del XX, se promulgaron un conjunto de normas tendentes a perfeccionar el proceso de descentralización y a consolidar la posición jurídica de las entidades territoriales ${ }^{15}$, si bien es cierto que a lo largo de este período histórico dichas entidades tuvieron como misión ejecutar administrativamente la voluntad del Estado central. Pero los buenos augurios que se cernían sobre el proceso descentralizador se vieron truncados en la década de los treinta, debido a la entrada en escena del retrógrado «Régimen de Vichy".

Tras este paréntesis en la peculiar historia del proceso de descentralización en Francia, el proyecto constitucional de la IV República, de 19 de abril de 1946, dedicaba un título a las «Colectividades Locales» (municipios, departamentos y territorios de ultramar). Tras

${ }^{14}$ Conviene aclarar que el desarrollo de las libertades locales constituyó una tradicional reivindicación de los liberales gracias, sobre todo, a la gran influencia que tuvo la obra y el pensamiento de Alexis de Tocqueville. Este autor, como es conocido, defendió en todo momento la importancia de los «cuerpos intermedios» o contrapoderes. Sus vivencias en Estados Unidos le llevaron a defender la democracia próxima al ciudadano, ya que según Tocqueville es en el municipio donde reside la fuerza de los pueblos libres.

${ }_{15}$ En este sentido hay que señalar que las Leyes de 10 de octubre de 1871 y de 5 de abril de 1884 supusieron, tanto para los departamentos como para los municipios, respectivamente, un paso decisivo hacia la emancipación y el reconocimiento del libre ejercicio de competencias. 
el fallido proyecto constitucional de abril de 1946, fue aprobada la Constitución de 27 de octubre del mismo año, cuyo Título X, relativo a las «Colectividades Territoriales», proclamaba en el art. 87 el principio de libre administración de éstas.

La entrada en vigor, ya durante la V República, de la Constitución de 1958, como vamos a tener la oportunidad de ver en lo sucesivo, constituye el punto de partida para entender la estructura y la idiosincrasia de la actual organización territorial en Francia ${ }^{16}$. El desarrollo legal y normativo de los postulados de la Constitución francesa de 1958 (en adelante, CF) en este punto se ha visto acompañado en todo momento por una clara voluntad política de impulsar el proceso de descentralización ${ }^{17}$. Al respecto, destaca la promulgación de la Ley de 2 de marzo de 1982 sobre los derechos y libertades de los municipios, departamentos y regiones, que introdujo un triple cambio trascendental en el devenir de las colectividades territoriales: la supresión de la tutela administrativa ${ }^{18}$, el traspaso del poder ejecutivo

16 Tras la segunda mitad del siglo $\mathrm{xx}$, la revolución industrial dará lugar a un escenario neo-liberal en el que dichas entidades se convertirán en un instrumento de dirigismo y planificación económica estatal, tal y como señala GILLI J.P., Les aspects administratifs de la régionalisation, Ed. Cujas, Paris, 1975, págs. 5 a 18. Esta evolución tuvo su reflejo en la práctica política de antaño. Así, en 1950 se creó, dentro del Ministerio de la Reconstrucción, la "Dirección General de la Ordenación del Territorio". En 1955, un Decreto reguló el establecimiento de diversos programas de acción y desarrollo regional. Finalmente, cabe destacar que en 1958 se pusieron en marcha los "Planes regionales de desarrollo económico y social y de ordenación del territorio".

17 Sobre este particular destacamos tres casos: a) Bajo el mandato de Georges Pompidou, se impulso decididamente la creación de una nueva entidad territorial: la región. Según el Presidente Pompidou, la región debe ser concebida como la unión de departamentos que va a permitir la realización y la gestión racional de los grandes equipamientos colectivos. Esta decisión política tendría su concreción jurídica en julio de 1972, con la publicación de la Ley sobre creación y organización de las regiones; b) En 1975, bajo el mandato de Giscard d'Estaing, se constituyó una Comisión, presidida por M. Olivier Guichard, con el fin de reflexionar sobre las competencias y los nuevos retos de las entidades locales. Los trabajos de esta Comisión tendrían su continuidad con el proyecto de ley presentado por el Gobierno en 1978, cuyo objeto era conseguir un mayor grado de libertad, de claridad en el reparto de competencias, de eficacia y de participación de los ciudadanos en el ámbito local. Finalmente, el texto del proyecto no vio la luz debido a que, posiblemente, fue víctima de un ambicioso intento por parte del Gobierno de tratar de regular en un sólo texto legal el proceso de descentralización (BODINEAU P. et VERPEAUX M., Histoire de la décentralisation, op. cit. pág. 74), Sobre los trabajos desarrollados por la Comisión Guichard puede verse a VIE J.E., La décentralisation sans illusion, Presses Universitaires de France, Paris, 1982, págs. 70 a 88 ; y c) En 1981, François Miterrand declaraba que Francia necesita tanto un poder fuerte y central para hacerse como un poder descentralizado para no deshacerse.

${ }_{18}$ En relación a este punto fue promulgada la Ley de 22 de julio de 1982, complementaria a la Ley de 2 de marzo del mismo año. En virtud de la nueva normativa, 
del prefecto a los presidentes de los consejos de representantes elegidos y la consagración de la región como colectividad territorial. Esta Ley fue desarrollada por una serie de normas complementarias con el fin de poner en marcha las medidas previstas y, por tanto, de perfeccionar el proceso de descentralización iniciado ${ }^{19}$.

\title{
III. LAS BASES CONSTITUCIONALES DE LA DESCENTRALIZACIÓN: REFERENCIA A LA REFORMA CONSTITUCIONAL DE 2003
}

Desde una perspectiva netamente constitucional, las dos bases sobre las que pivota el proceso de descentralización en Francia son: de una parte, los principios de unidad e indivisibilidad de la República, previstos en los arts. 2 y $3 \mathrm{CF}$ (si bien la fórmula constitucional sólo habla de la indivisibilidad de la República ${ }^{20}$; y, de otra, el principio de libre administración de las colectividades territoriales, consagrado en los arts. 34 y $72 \mathrm{CF}$. El futuro del proceso de descentralización en Francia se fundamenta, en gran medida, en la capacidad para conjugar estos principios, habida cuenta de que la unidad e in-

\begin{abstract}
los medios de tutela administrativa y financiera del Estado sobre los actos de las colectividades territoriales son suprimidos a cambio de un control de legalidad a posteriori ejercido por los prefectos y los tribunales administrativos. Por lo que respecta al control financiero, se crean las Cámaras de Cuentas regionales, un nuevo mecanismo jurisdiccional de control presupuestario y de la gestión de las colectividades territoriales.

${ }^{19}$ Así, cabe mencionar las siguientes disposiciones: a) Leyes de 26 de enero de 1984 y de 13 de julio de 1987, por las que se regula el estatuto de la función pública territorial; b) Ley de 5 de enero de 1988, sobre las competencias económicas de las colectividades territoriales; c) Ley de 13 de mayo de 1991, reguladora del Estatuto territorial de Córcega; d) Ley de 3 de febrero de 1992, por la que se aprueba el estatuto y las condiciones de ejercicio de los mandatos de los elegidos y representantes locales; e) Ley de 6 de febrero de 1992, relativa a la administración territorial de la República; f) Ley de 5 de febrero de 1995, por la que se crean los «pays», unas nuevas entidades creadas por los territorios descentralizados para la defensa de sus intereses; g) Ley de 19 de marzo de 1999, sobre el modo de elección de los consejos regionales; h) Ley de 25 de junio de 1999, de orientación para la coordinación y el desarrollo territorial; i) Ley de 12 de julio de 1999, relativa al reforzamiento y simplificación de la cooperación intermunicipal. j) Ley de 5 de abril de 2000, sobre el ejercicio del mandato de los representantes territoriales; k) Ley de 22 de enero de 2002, por la que se refuerza la autonomía reglamentaria de la Asamblea de Córcega; y l) Ley de 27 de febrero de 2002 , relativa a la democracia de proximidad.
\end{abstract}

Sobre el contenido sintético de estas leyes puede verse Gestions Publiques en Revues, n. $^{\circ}$ 2, 2002-2003.

${ }_{20}$ Esta cuestión ha sido estudiada por HOUTEER C., Recherches sur les bases constitutionnelles de la décentralisation territoriale (Tomo II), op. cit. págs. 568 a 574 . 
divisibilidad juegan, a priori y en cierto modo, como un elemento limitador y condicionante de cualquier tendencia descentralizadora ${ }^{21}$.

\section{La unidad e indivisibilidad de la República}

La proclamación de ambos principios tuvo lugar, por primera vez, en la Convención de 25 de septiembre de $1792^{22}$. Como es bien sabido, dichos principios son una herencia de la ideología liberal de la época que pretendió suprimir cualquier cuerpo intermedio entre el Estado y la sociedad. Los liberales concibieron la democracia como una unidad del pueblo tendente a la consecución de la plena igualación de las condiciones de vida, de aquí que el carácter único e indivisible de la soberanía se proyecte sobre la legitimidad democrática.

El Consejo Constitucional francés ha señalado, en una prolija y contundente jurisprudencia, que los arts. 2 y $3 \mathrm{CF}$ constituyen uno de los límites principales a la descentralización ${ }^{23}$. De entre dicha jurisprudencia destaca la Decisión n..$^{\circ} 274$, de 20 de mayo de 1990, en la que el Consejo Constitucional esgrime el principio de indivisibilidad de la República para afirmar el valor constitucional de la soberanía del pueblo, declarando la interrelación entre la indivisibilidad de la República y la unidad de dicha soberanía. Este razonamiento le lleva a afirmar que el principio de autonomía de las entidades territoriales es puramente administrativo y que en ningún caso implica el ejercicio de los poderes clásicos del Estado, a excepción de las atribuciones delegadas por éste ${ }^{24}$.

Efectivamente, la unidad de la República implica la existencia de un poder central único y una organización administrativa uniforme, en virtud de la cual las colectividades descentralizadas se someten al

${ }^{21}$ Sobre este aspecto puede consultarse a ZOCO ZABALA C., «Revisión constitucional en Francia: la redifinición del modelo de descentralización administrativa», en Revista Española de Derecho Constitucional, n. ${ }^{\circ}$ 72, 2004, págs. 163 a 186.

22 Es cierto que ya la Constitución monárquica de 3 de septiembre de 1791 afirmaba en el art. 1 del Título II ( «De la división del Reino y del Estado de los ciudadanos»), que "el Reino es uno e indivisible».

${ }^{23}$ Sobre la jurisprudencia constitucional en la materia consúltese a TOUVET L. et FERSTENBERT J., Les grands arrêts du Droit de la décentralisation, Dalloz, Paris, 2001, págs. 36 a 48 .

${ }_{24}$ Como afirman F. LUCHAIRE et Y. LUCHAIRE, "las colectividades descentralizadas no tienen más que funciones de administración, mientras que las de los Estados miembros de una federación van mucho más allá; la colectividad territorial se administra pero no se gobierna a sí misma». (Le Droit de la décentralisation, op. cit. pág. 98). 
poder del legislador estatal y a una estructura administrativa homogénea que conlleva, a su vez, la sumisión de los ciudadanos a un régimen jurídico idéntico (unidad de la República-Estado unitario e uniformidad del Derecho aplicable). A lo hay que añadir que el Estado tiene la potestad de orientar la acción de las colectividades territoriales con el fin de preservar el interés general ${ }^{25}$.

Por su parte, la indivisibilidad de la República supone, en sentido estricto, que ninguna colectividad dispone de una cuota de poder soberano y que cualquier «intento federalizante» sería contrario a los principios esenciales del sistema jurídico-político francés. La mayoría de la doctrina francesa entiende, con Duguit a la cabeza, que la indivisibilidad de la República hace referencia a la indivisibilidad de la soberanía ${ }^{26}$, del sistema normativo de fuentes y de los poderes ejecutivo y legislativo.

Ahora bien, el alcance de los dos principios a los que se acaba de hacer mención debe ser modulado tras la ley constitucional de 2003, con el fin de hacerlos compatibles con el "principio de diversidad territorial» - previsto en el art. $72 \mathrm{CF}$-, en virtud del cual se hace plausible la consagración de nuevas colectividades territoriales - tal y como ha sucedido con la constitucionalización de las regiones-, así como la sustitución de las colectividades preexistentes.

\section{El principio de libre administración de las entidades territoriales}

$\mathrm{El}$ art. 34.4 CF dispone: «La ley determina los principios fundamentales (...) a la libre administración de las colectividades locales, de sus competencias y de sus recursos». Esta disposición se complementa con el art. 72.2 CF, según el cual «estas colectividades se administran libremente por sus Consejos de representantes y dentro de las condiciones previstas en la ley» ${ }^{27}$.

${ }^{25}$ Los rasgos que debe tener la organización unitaria de un Estado han sido apuntados por el prof. DELPÉRÉE F., «La décentralisation à la belge et à la française», en AAVV., La Constitution et les valeurs, Mélanges en l'honneur de Dmitri Georges Lavroff, Dalloz, Paris, 2005, págs. 141 a 150.

26 Como sostiene acertadamente G. MARCOU, el principio de indivisibilidad es la base constitucional que explica el carácter unitario del Estado y que sirve de fundamento de la unidad del pueblo francés. ( Le principe d'indivisibilité de la République», en Pouvoirs, Revue Française d'Études constitutionnelles et politiques, n. ${ }^{\circ} 100$, 2002, págs. 45 y 46.

${ }^{27}$ De los preceptos que se acaban de citar destaca un dato que, en principio, puede pasar desapercibido pero que, en realidad, podría tener cierta relevancia y 
Al igual que dijimos que sucedía con la unidad e indivisibilidad de la República, el principio de la libre administración de la colectividades territoriales tiene un importante valor y alcance constitucional, tal y como se ha encargado de declarar la jurisprudencia del Consejo Constitucional francés ${ }^{28}$. De hecho, el enunciado de este principio puede proclamarse, incluso, frente al de descentralización; por ello, cabría decir que mientras la descentralización es el género, el principio de libre administración constituye la especie. De esta forma, si la descentralización supone un proceso en virtud de cual el Estado tiende a reducir sus atribuciones y a transferirlas a las entidades territoriales, controlando el ejercicio de las mismas, la libre administración, por su parte, no conllevva transferencia alguna del Estado, ya que presupone que dichas entidades disponen de un cierto número de atribuciones y de competencias que le son consustanciales ${ }^{29}$. Es decir, desde una perspectiva constitucional, este principio sólo tiene sentido si se parte de la idea de que las autoridades locales deben disponer del conjunto de medios jurídicos necesarios para el ejercicio de sus funciones y competencias ${ }^{30}$. Ahora bien, el principio de libre administración va a estar supeditado, en gran medida, a la voluntad de la Ley, lo que conlleva a un reparto legal de competencias, pero no a un reparto de competencias legales.

En resumen, mientras que la descentralización funciona como una técnica de reparto de poderes entre la administración central y local, cuyo límite más visible es la unidad e indivisibilidad ( Constitución administrativa»), la libre administración queda configurada

trascendencia práctica. Nos referimos a la diferencia entre colectividades locales y territoriales, términos empleados, respectivamente, por el art. 34 y 72 CF. Ambas expresiones no son exactamente sinónimas dado que la segunda tiene un alcance y significado mucho más general que la primera. De esta forma, cabría afirmar que las entidades locales son los municipios y los departamentos, mientras que las colectividades territoriales son estas dos entidades más los territorios de ultra mar y las regiones.

$28 \mathrm{Al}$ respecto, destaca la Decisión del Consejo Constitucional n. ${ }^{\circ} 83-168$, de 20 de enero de 1984. Vid. TOUVET L. et FERSTENBERT J., Les grand arrêts du droit de la décentralisation, op. cit. págs. 3 a 10. Para un estudio más exhaustivo, véase a PAVIA M.L., «À propos de l'autonomie territoriale et de la libre administration territoriale: l'impossible comparaison entre les droits constitutionnels espagonol et français? », en AAVV (Ed. FERNÁNDEZ SEGADO F.)., La Constitución Española en el contexto constitucional europeo, Dykinson, Madrid, 2003, págs. 2201 a 2215.

${ }^{29}$ A ello hay que unir que la libre administración no supone una simple libertad de gestión y ejecución, sino una libertad deliberativa y de ejecución plena y autónoma.

30 Consúltese a BROSSET E., "L'impossibilité pour les collectivités françaises d'exercer le pouvoir législatif à l'épreuve de la révision constitutionnelle sur l'organisation décentralisée de la République», en Révue Française de Droit Constitutionnel, n. ${ }^{\circ}$ 60, 2004, pág. 696 . 
como una libertad que toparía con el principio de igualdad territorial ( Constitución política») ${ }^{31}$, tal y como se ha encargado de recordar el Consejo Constitucional ${ }^{32}$.

\section{La reforma constitucional de 2003 y su desarrollo legislativo}

La reforma constitucional de octubre de 2003, relativa a la organización descentralizada de la República, tuvo claramente tres objetivos: consagrar el principio de descentralización, reconocer el derecho de las colectividades territoriales a la experimentación en materia legal y reglamentaria y, por último, garantizar a éstas como entidades de pleno Derecho.

El cariz constitucional que adoptó en 2003 el proceso de descentralización en Francia es fruto de un proceso de impulso político que requiere, no obstante, del necesario desarrollo legislativo para llevarlo a efecto. En este sentido, hasta el momento se han publicado una serie de leyes con este fin.

a) Ley de 28 de marzo de 2003, relativa a la organización descentralizada de la República. Los principios constitucionales que introduce esta ley son: la experimentación, la subsidiariedad y el poder reglamentario. Dado que las dos primeras han sido objeto de una regulación más específica, como veremos en su momento, convendría analizar someramente el ejercicio de la potestad reglamentaria.

Como premisa es preciso señalar que el poder reglamentario es una facultad que el Estado reconoce y delega a las entidades territoriales, lo cual significa que no es un poder inherente a las mismas puesto que requiere de la correspondiente habilitación legal. La libre administración, como declaró el Consejo Constitucional en su Decisión de 17 de enero de $2002^{33}$, implica la posibilidad de conferir a las colectividades territoriales un poder reglamentario de aplicación de la

31 En este punto seguimos a FAVOREU L., "Les bases constitutionnelles de la décentralisation", en AAVV (Dirs. MOREAU J. et VERPEAUX M.)., Revolution et decentralisation. Le systeme administratif français et les principes revolutionnaires de 1789, op. cit. págs. 86 a 89. Para tener una visión más profunda de la diferencia entre libre administración y descentralización consúltese a DOUMERT E., L'organisation de la République est décentralisée, Tesis Inédita, Université Paris I, curso 2003-2004.

${ }_{32}$ Véanse, por todas, las Decisiones 84-185, de 18 de enero de 1985, y 2001-454, de 17 de enero de 2002.

${ }^{33}$ Vid. Magnon X., «Le pouvoir réglamentaire des collectivités territoriales. Nouveau bilan après la Décision du Conseil Constitutionnel du 17 janvier 2002 sur le Statut de la Corse», en Révue de la Recherche Juridique, n. ${ }^{\circ} 4,2003$, págs. 2757 a 2786. 
ley. De todas formas, convendría distinguir al respecto dos tipos de reglamentos: los reglamentos de ejecución, encargados de fijar y concretizar las modalidades de aplicación de la ley; y los reglamentos de aplicación, en virtud de los cuales el legislador se limita a fijar el objeto y los principios relativos a su puesta en práctica, lo que supone para el titular de la potestad reglamentaria un mayor margen de maniobra a la hora de aplicar la ley.

b) Ley de 1 de agosto de 2003, relativa a la experimentación por parte de las colectividades territoriales. Según el remozado art. 72.4 CF, las colectividades territoriales pueden suspender a título experimental las disposiciones legislativa y reglamentarias que afecten al ejercicio de sus competencias. El principal problema con el que se encuentra la aplicación práctica del derecho de experimentación es el de su difícil conciliación con el principio de igualdad de los ciudadanos ante la ${ }^{l e y}{ }^{34}$, de ahí que el constituyente haya previsto una serie de límites materiales y temporales. Desde un punto de vista material, la experimentación no puede aplicarse cuando estén en juego las condiciones esenciales de ejercicio de libertades públicas y derechos fundamentales constitucionalmente garantizados. Desde un punto de vista temporal, la provisionalidad del derecho a la experimentación permite diferenciarla de la derogación, cuyos efectos son permanentes.

En cualquier caso, la experimentación no es la mejor forma de conciliar la democracia local con la unidad republicana ${ }^{35}$. En este sentido, el primer ministro Lionel Jospin declaraba ante la Asamblea Nacional, en enero de 2001, que la experimentación «debe procurar que la cohesión social y la equidad entre las diferentes colectividades, que garantizan a cada ciudadano un servicio idéntico sobre el conjunto del territorio, no sean puestas en cuestión. Esto es así porque el Gobierno es contrario a una descentralización a la carta que concederá ventajas a las colectividades más ricas y pudientes, en detrimento de las otras. El principio de igualdad republicana debe estar presente en este tema. Es por ello por lo que la noción de experimentación debe ser recibida con cautela».

Pese a esta afirmación, no hay que olvidar que la nueva regulación constitucional deja en manos del legislador estatal la regulación de la

${ }^{34}$ Como apunta acertadamente DRAGO G, «la regulación de la experimentación en la Constitución la sitúa al mismo nivel normativo que el principio de igualdad». ( Le droit à l'expérimentation", en AAVV (Dirs. GAUDEMET Y. et GoHIN O.)., La République décentralisée, Edition Panthéon-Assas, Paris, 2004, pág. 80.

${ }^{35}$ LAYER F., "Histoire d'une recontre: décentralisation et constitution", en Révue de la Recherche Juridique, n. ${ }^{\circ}$ 2, 2003, pág. 1116. 
facultad de experimentación, lo que supone gartantizar la unidad y la seguridad jurídica en esta materia. No obstante, también conviene señalar que la autorización del legislador central para proceder a la suspensión de una norma en un determinado territorio no es más que una forma de compensar la falta de potestad legislativa de las colectividades territoriales ${ }^{36}$.

c) Ley de 1 de agosto de 2003, relativa al referéndum local. En virtud del actual art. 72.1 CF, el referéndum local debe versar sobre proyectos de resolución o actos relativos al ámbito de competencia del órgano deliberante o ejecutivo de la colectividad territorial; además es decisorio, si bien no se reconoce iniciativa popular para convocarlo, debiendo ser una ley orgánica la que establezca las condiciones en las que tiene que desarrollarse la consulta. Con independencia de ello, resulta indudable que la proclamación del reférendum local demuestra una clara tendencia hacia el reconocimiento de un considerable grado de autonomía para las entidades locales.

d) Ley de 29 de julio de 2004, relativa a la autonomía financiera de las colectividades territoriales ${ }^{37}$. Esta ley tiene su fundamento en el vigente art. 72.2 CF, que tras la reforma establece que el principio de autonomía financiera de las colectividades territoriales se fundamenta en la disponibilidad de recursos propios, tanto desde un punto vista material y técnico como financiero. Además de la disponibilidad de recursos, el constituyente reconoce en el citado precepto que serán administrados libremente por las colectividades territoriales; eso sí, de acuerdo con las condiciones fijadas por la ley. Pero el auténtico valor y el verdadero alcance de la reforma reside en que prevé un sistema de compensación cuando la colectividad territorial ejerza competencias transferidas previamente por el Estado ${ }^{38}$. De nada serviría reconocer nuevas facultades de actuación a las en-

${ }^{36}$ No faltan autores que opinan que la potestad de suspensión experimental de una ley no es otra cosa que ejercer el poder legislativo. En este sentido véase a BRosSET E., "L'impossibilité pour les collectivités territoriales françaises d'exercer le pouvoir legislatif à l'éprevue de la révision constitutionnelle sur l'organisation décentralisée de la République», op. cit. pág. 707.

37 Para tener una visión más completa de este principio con anterioridad a la vigencia de dicha Ley consúltese a MÜLLER R., Descentralización político-financiera en Francia, Serie Política Fiscal, n. ${ }^{\circ}$ 74, 1995.

38 Para mayor abundamiento, véase sobre este tema a GANDREAu S., "Quelle autonomie de ressources pour les collectivités territoriales?", en Révue Générale des Collectivités Territoriales, n. ${ }^{\circ} 27,2003$, págs. 578 a 591; y ORAISON A., "Commentaires critiques des dispositions financières et fiscales introduites dans le charte suprême de la Vème Républilque par l'article 7 de la loi constitutionnelle du 28 de mars 2003", en Révue de la Recherche Juridique, n. ${ }^{\circ}$ 2, 2004, págs. 1328 a 1344. 
tidades territoriales si éstas no van acompañadas de la transferencia de los recursos necesarios para poder llevarlas a cabo ${ }^{39}$.

Con independencia de lo anterior, lo cierto es que para que podamos hablar, en sentido estricto, de descentralización, resulta necesario que los recursos propios dependan de una decisión adoptada por la colectividad afectada y no de las transferencias del Estado, las cuales deben ser, en todo caso, complementarias ${ }^{40}$. Es decir, lo más importante es que dichos recursos puedan ser administrados libremente por las Asambleas de representantes locales. Para satisfacer esta demanda el legislador reconoce un auténtico poder fiscal a estas colectividades que va más allá de la mera transferencia de impuestos estatales, al permitirles fijar legalmente la base imponible y la cuota de dichos impuestos. En otras palabras: «no sólo hay un reparto del producto fiscal entre el Estado y las colectividades territoriales, sino que también hay un reparto del poder fiscal $»^{41}$.

e) Ley de 13 de agosto de 2004, relativa a la libertad y responsabilidad local. Pese a que esta Ley proclama la «subsidiariedad descendente», muestra asimismo una clara voluntad de mantener el papel preponderante del Estado cuando habla de responsabilidades de las entidades territoriales en lugar de competencias ${ }^{42}$, en la medida en que sólo estas últimas suponen un ámbito de dominio y un poder de intervención autónomos. Con todo, convendría matizar que el principio de subsidiariedad, per se, no funciona como un instrumento de reparto de competencias entre el Estado y las colectividades territoriales, sino que sirve más bien para clarificar cuál es la instancia idónea para lograr una gestión más eficaz.

\section{CONCLUSIONES: ALCANCE Y PERSPECTIVAS DEL PROCESO DESCENTRALIZADOR EN FRANCIA}

El definitivo impulso y el desarrollo efectivo del proceso de descentralización en Francia exige, ante todo, un importante esfuerzo por

${ }^{39}$ En relación al proceso de descentralización en materia de competencias pueden verse las actas del Colloque National du GRALE, La décentralisation en mouvement, 12 et 13 janvier 2006, Assemblée Nationale, Paris.

40 Esta opinión ha sido mantenida por BazIadoly S., «La Charte européenne de l'autonomie locale et l'autoomie financiére des collectivités locales françaises», en Révue Générale des Collectivités Territoriales, n. ${ }^{\circ} 29,2003$, pág. 721.

41 Tomamos la cíta de BoN P., «Las recientes reformas territoriales francesas», en Revista Aragonesa de Administración Pública, n. ${ }^{\circ} 22,2003$, pág. 619.

42 Vid.Milano L., "La loi du 13 août 2004 relative aux llibertés et responsabilités locales, premier jalon de la réorganisation de l'Etat», en Révue Génerale des Collectivités Territoriales, $n .^{\circ} 33,2005$, pág. 92. 
afrontar una serie de disyuntivas, ya clásicas, que han venido lastrando dicho proceso, pero que a su vez permiten detectar las deficiencias del mismo ${ }^{43}$. La primera disyuntiva se refiere a la diferencia entre la descentralización y la democracia, dado que mientras ésta parte de una concepción claramente política, la primera ha venido siendo concebida en Francia en términos administrativos. La segunda es la puesta de los métodos de la descentralización funcional al servicio de la descentralización territorial. Y la tercera consiste en la diferenciación entre la descentralización y la noción de asuntos locales.

Para dar respuesta a estas disyuntivas la propuesta de soluciones transaccionales puede ser de gran utilidad. De esta forma, sería conveniente que la clásica «República jacobina centralizada» diera paso a una «República territorial» a través de la reinterpretación de los principios de unidad e indivisibilidad ${ }^{44}$. Esta última opción fue apoyada en su momento por el entonces primer ministro Lionel Jospin, quien en una comparecencia ante la Asamblea Nacional, en enero de 2001 , afirmaba que "dado que la solidaridad nacional tiene su fundamento en el pacto republicano, Francia permanecerá como un Estado unitario. Pero la unidad no significa uniformidad: cada territorio debe poder poner en marcha sus logros de la forma que mejor convenga a las necesidades de sus habitantes».

A la vista de todo lo dicho, resulta palmario que la reforma constitucional operada en Francia posee una impronta programática e idealista que convierte al legislador orgánico en el protagonista para dotar al proceso de descentralización de "realismo jurídico " ${ }^{45}$; otra cosa es que el reconocimiento constitucional de una serie de «nuevos principios» sirva para impulsar una «nueva dinámica» que permita al Estado evolucionar y desprenderse del ejercicio de sus potestades regalianas $^{46}$. O lo que es lo mismo, pese a su título, la ley constitucional relativa a la organización descentralizada de la República no descentraliza pero permite descentralizar ${ }^{47}$.

${ }^{43}$ MeNY Y., Centralisation et décentralisation dans le débat politique français (19451969), op. cit. pág. 25.

${ }_{44}$ Esta alternativa ha sido propuesta por LAYER F., "Histoire d'une recontre: décentralisation et constitution», op. cit. pág. 1110.

${ }^{45}$ FAure B., «Réforme constitutionnelle et décentralisation: des slogan font loi», en Révue du Droit Public, n. ${ }^{\circ}$ 1, 2003, pág. 122.

${ }^{46}$ RiHAL H., "Le statut constitutionnel des collectivités territoriales issu de la loi constitutionnelle du 28 de mars 2003: entre innovation et complesité», en Révue Française D'Administration Publique, n. ${ }^{\circ} 105,2003$, pág. 234.

${ }^{47}$ LuchaIre Y. et LuchaIre F., Décentralisation et Constitution, Ed. Economica, Paris, 2003, pág. 63 . 
Sin embargo, para que este proceso pueda llegar a buen puerto es imprescindible que la opinión pública y la clase política francesa sean capaces de desprenderese de una serie de prejuicios en torno a la descentralización, como son, entre otros, el riesgo de desvirtuar el carácter unitario del Estado, la introducción de discriminaciones de trato en función del territorio que se habite, el aumento del déficit presupuestario de las colectividades territoriales con el fin de reducir el estatal y la inseguridad que generaría la multiplicación de los niveles de decisión.

$$
* * *
$$

